\title{
Growth Behavior of Retinotectal Axons in Live Zebrafish Embryos under TTX-Induced Neural Impulse Blockade
}

\author{
Rolf J. Kaethner and Claudia A. O. Stuermer* \\ Faculty of Biology, University of Konstanz, D-78434 Konstanz, Germany
}

\section{SUMMARY}

The growth dynamics of individual DiO-labeled retinal axons deprived of normal neural impulse activity by TTX was monitored in the tectum of living zebrafish embryos with time-lapse video microscopy and compared with normal active axons. Growth cones of TTX-blocked axons advance intermittently with an average velocity similar to normal axons. While exploring their local environment, they are broadened and bear ruffling lamellipodia and filopodia, but become streamlined when advancing. The activity-deprived axons grow directly towards their retinotopic target sites in the tectum as do their normal counterparts and very rarely extend branches en route. Much like normal axons, TTXblocked axons begin to branch and develop their terminal arbors only at their retinotopic target area. They emit and retract numerous short side branches over a period of several hours. Thearea they contact (the "exploration field") is of similar dimension as that of active axons, covering from $1 \%$ to $7.4 \%$ of the tectal neuropil surface, but the final arbors cover an area only one-half to onesixth as large. TTX arbors are as small as arbors of normal active axons and retinotopically correct. Thus, the typical exploratory growth behavior of developing retinal axons in the tectum, the dynamics of terminal arbor formation at retinotopically correct sites, the dimension of the exploration field, and the shaping of the arbors in zebrafish embryos are unaffected by TTX-induced neural impulse blockade. (c) 1994 John Wiley \& Sons, Inc.

Keywords: exploratory growth, terminal arbor exploration field, terminal arbor size, activity-deprived embryos, time-lapse video microscopy, retinotopic map.

\section{INTRODUCTION}

The establishment of cell-specific pathways and target connections in the developing brain depends on the navigational performance of the growing axons. In the vertebrate retinotectal system, the retinal axons are led by a single growth cone over a substantial portion of their path (Holt and Harris, 1993). Here, and in other neuronal systems, the growth cones are small compared to the distance they cover (Chien et al., 1993; Baier and Bonhoeffer, 1992). Growth cones are quite efficient in

Received November 24. 1993: accepted January 27, 1994

\footnotetext{
* To whom correspondence should be addressed.
}

reading and interpreting cues in their local environment (Holt and Harris, 1993; Goodman and Shatz, 1993). They obviously are equipped accordingly with a variety of receptors and the machinery for intracellular signal transduction (Strittmacher and Fishman, 1991). The filopodia radiating from the growth cone apparently play an essential role in reading and perhaps in interpreting guidance cues. As has recently been demonstrated in the Xenopus visual system, retinal growth cones commit severe pathway mistakes when their filopodia are disrupted (Chien et al., 1993). This recent finding is consistent with previous observations that growth cones acquire a complex morphology displaying numerous filopodia at "decision" points along their path (Tosney and Landmesser, 1985; Bovolenta and Mason, 1987). Growing axons are also able to propagate action potentials (Meister et 
al., 1991), and release transmitter substances (Young and Poo, 1983), so activity-mediated interactions with cells in their environment may in some systems also play a role during growth cone advance. However, retinal growth cones fulfill their navigational tasks along their path to the tectum correctly in the absence of neural impulse activity (Harris, 1984; Goodman and Shatz, 1993; Thompson and Holt, 1989). When retinal axons arrive at the tectum they must establish synaptic contacts with a limited number of tectal neurons, that is, with neurons in a position that correlates topographically with the position of the axon's parent ganglion cell in the eye. Therefore, the retinal axons that traveled in close association with one another during their path through the optic nerve and tract have to individually select their specific tectal target sites.

It is now widely accepted that the tectum carries positional markers that guide the axons. These markers may be expressed over the axes of the tectum in concentration gradients (Gierer, 1987; Bonhoeffer and Gierer, 1984), as was demonstrated for the repulsive guidance component (Walter et al., 1987; Baier and Bonhoeffer, 1992). This guidance component appears to be evolutionarily conserved and to influence axons from the temporal retinae in fish (Vielmetter and Stuermer, 1989), frogs (Jack et al., 1991), birds (Walter et al., 1987), and mammals (Godement and Bonhoeffer, 1989). Moreover, the final order of retinal axon terminals, that is, the retinotopic map, obeys similar rules in all vertebrate classes (Holt and Harris, 1993), suggesting that further positional markers-as yet unidentified-may be also conserved.

The developmental events preceding the establishment of a precisely organized map, however, differ markedly along species (Goodman and Shatz, 1993). Retinal axons in rats, for instance, initially branch widely over the superior colliculus, and only gradually withdraw branches from retinotopically inappropriate territories (Simon and O'Leary, 1992). The same is true of axons in the chick tectum (Nakamura and O'Leary, 1989). In birds, the retraction of side branches and pruning of the axon terminal arbors proceed only in the presence of neural impulse activity and are inhibited or delayed by the sodium channel blocker tetrodotoxin (TTX) (Kobayashi et al., 1990). Normal impulse activity is also needed in another visual target center, the lateral geniculate body ( $L G N$ ) in cats, to restrict retinogeniculate axon arbors to their appropriate eye-specific layer (Shatz and Stryker, 1988; Sretavan et al., 1988). Quite different from this pattern are retinal axons in developing zebrafish, which form small terminal arbors only over retinotopic target territories (Stuermer, 1988). As judged from fixed brains, the axons are target directed and project no side branches into the distant tectum. This is also true of embryos deprived of all Na-channel-dependent activity by TTX (Stuermer et al., 1990).

More recently, the combination of fluorescent nerve fiber tracing and time-lapse video microscopy has enabled us to observe the growth of retinal axons in the tectum of living zebrafish embryos directly (Kaethner and Stuermer, 1992). The video films revealed previously unseen phases of exploratory behavior by both the advancing growth cone and the developing terminal arbors. En route to the retinotopic target sites, growth cone advance is intermittent and involves remarkable and periodic changes in shape (Kaethner and Stuermer, 1992). When not advancing, growth cones are complex and extend numerous filopodia and ruffling lamellipodia into their surroundings. This exploratory phase of a growth cycle lasts from a few minutes to several hours and ends with the extension of a long filopodium in the direction of the target. The growth cone then becomes streamlined and moves rapidly along its filopodium to a new position, where a new exploratory phase with growth cone enlargement takes place. Another exploratory phase begins when the growth cone reaches its retinotopic target. Upon arriving at the site, the growth cone halts and projects branches in various directions. Of the numerous branches that are projected over the next hours, many are also retracted, and a circular field of $1.5 \%-5.3 \%$ tectal surface area is explored (exploration field).

The greater temporal and spatial resolution of the video observation allowed reassessment of the growth and exploratory behavior of axons that were, throughout their growth in the tectum, silenced by TTX. In the present study, we monitored the growth of individual retinal axons in the tectum of living embryos that were entirely paralyzed for days by a single TTX injection (Stuermer et al., 1990). This investigation was undertaken to determine whether retinal axons developing under TTX-induced neural impulse blockade would change their pulsatory growth while progressing toward their retinotopic target sites. Particularly, we examined the exploratory growth cone behavior during nonadvancing phases and the velocity of filopodial emission. Attention was also paid to the retention times of transient branches, their possi- 
ble projection into distant areas of the tectum, and the shaping of the final arbor. Our results indicate that none of these parameters established in normal embryos differ in TTX-treated fish.

\section{METHODS}

Observations of growing retinotectal axons were performed in the mutant zebrafish embryo strain gol $1 /$ gol 1. which has-in contrast to wild-type embryos-transparent melanophores (Kaethner and Stuermer, 1992). This mutant was originally provided by Charles Kimmel, University of Oregon. Since the gol 1/gol I melanophores bear fewer black pigment granules, labeled axons can be viewed through the unopened skull. Adult fish and embryos were kept on 14:10 h light/dark cycles at $28^{\circ} \mathrm{C}$. Eggs were collected after spontaneous spawning. For experimental manipulations prior to hatching, which occurs from about $72 \mathrm{~h}$ postfertilization (PF) onwards, embryos were removed from their egg cases with pointed forceps and kept in water in small petri dishes.

\section{TTX Injection}

TTX injections were as described in Stuermer et al. (1990). Embryos between 30 and $38 \mathrm{~h}$ PF received injections of $8-10 \mathrm{nl} 0.12 \mathrm{mM}$ Tetrodotoxin (Sigma) in Ringer's solution into one eye, delivered through a calibrated glass needle with pressure. Following these injections most embryos were entirely paralyzed except for their heartbeat. Embryos that twitched upon touch during dye application or at the beginning or during the recording session were discarded from further analysis and killed by an overdose of the anesthetic MS222 (Sigma). That TTX injections block electrical activity was demonstrated by electrophysiological recordings in our earlier study (Stuermer et al., 1990). In embryos paralyzed by TTX, no neural activity was found in either the tectum or subtectal regions. This activity blockade lasted up to $140 \mathrm{~h}$ PF. Electrical activity was present, however, in embryos that twitched upon touch. Thus, the paralysis of embryos concurs with the absence of electrical activity in their retinotectal system.

\section{Application of DiO}

Punctate applications of $\mathrm{DiO}\left(N, N^{\prime}\right.$-dioctadecyloxacarbocyanine 4-toluene sulfonate, Serva) into defined locations in the retina were as described in detail by Stuermer (1988) and Kaethner and Stuermer (1992) and resulted in one to a few labeled axons in the tectum.

The techniques of staining retinal axons and of live observations have been discussed in detail in our earlier report (Kaethner and Stuermer, 1992). The only difference to the earlier procedures was that the embryos here were TTX injected. They survived as well or even better than their normal but anesthetized counterparts and developed normally during the observation periods. That the injection of fluid per se does not cause developmental abnormalities was demonstrated earlier, when TTXinjected embryos were compared to Ringer-injected individuals and to uninjected fish (Stuermer et al., 1990). Therefore the only controls here were uninjected embryos of our earlier time-lapse study.

\section{In Vivo Time-Lapse Video Microscopy}

As detailed in our earlier report (Kaethner and Stuermer, 1992), embryos 52-97 h PF (Table 1) were placed on a coverslip in a position that allowed a dorsolateral view of the tectum opposite to the labeled eye. Most of the surrounding water was removed, except for a drop around the embryo and a silicon ring was placed around the embryo to prevent it from drifting. The embryo was covered with Voltalef oil (Atochem) and placed on a glass slide.

The microscope (Zeiss Axioplan) was equipped with Nomarski differential interference contrast (DIC) optics. epifluorescence filter sets for fluoresceine isothiocyanate, $20 \times, 40 \times, 100 \times$ oil immersion lenses, an infrared filter, and a 100-W Xenon lamp. Reduction of light exposure duration was through a shutter inserted into the light path which opened every $30 \mathrm{~s}$ for $200 \mathrm{~ms}$. Within the $200 \mathrm{~ms}$, three frames were shot, averaged, and enhanced with a digital image processor (Hamamatsu). The processed frames were received by a video recorder (Sony) connected to a time-lapse system (EOS). Boundaries of the tectal neuropil and adjacent brain areas (Stuermer, 1988 ) are visible with $20 \times$ lenses under Nomarski optics, permitting determination of the tectal position of the recorded axons. The entire extent of individual terminal arbors were monitored in different focal planes stepwise at the beginning and end of the recording session in real time. Single images were photographed or drawn from the screen of a monitor.

Drawings were made from the tectal neuropil at the end of a recording period. The surface area of neuropil, the area covered by an arbor, and the arbor's exploration field were determined. The arbor, exploration field area, and area of tectal neuropil were assessed by two methods. Lines were drawn to connect the tips of the branches and around the tectal neuropil. The long and short axes of the resulting shape (Stuermer, 1984, 1988) were used to calculate the elliptical area. The second method was performed in the following way. Grids of equal-sized squares were placed over the neuropil and arbors, and all "occupied" squares were counted and added. The squares were $1.3 \times 1.3 \mu \mathrm{m}$ for size determination of the arbors and their exploration fields, and $3.3 \times 3.3 \mu \mathrm{m}$ for the neuropil. The area value of the arbors and their exploration fields were expressed as a percentage of the neuropil area. For a comparison with arbor sizes determined in an earlier study (Stuermer, 1988), the long and short 
Table 1 Identification of Individual Axons

\begin{tabular}{|c|c|c|c|c|c|}
\hline Axon & $\begin{array}{c}\text { Embryo } \\
\text { (h PF) }\end{array}$ & $\begin{array}{c}\text { Growth Cone } \\
\text { (h PF) }\end{array}$ & $\begin{array}{l}\text { Length of } \\
\text { Observation } \\
\text { (h and } \mathrm{min} \text { ) }\end{array}$ & $\begin{array}{l}\text { Arbor } \\
\text { (h PF) }\end{array}$ & $\begin{array}{l}\text { Length of } \\
\text { Observation } \\
\text { (h and } \min \text { ) }\end{array}$ \\
\hline 1 & & $52.5-54.5$ & 2.00 & - & - \\
\hline 2 & & $55-56.5$ & 1.15 & - & - \\
\hline 3 & $52-65.5$ & $57.5-65.5$ & 8.10 & - & - \\
\hline 4 & & $62.5-64.5$ & 1.45 & - & - \\
\hline 5 & & $62.5-65.5$ & 2.50 & - & 一 \\
\hline 6 & 54.82 & $58-62.5$ & 4.20 & - & - \\
\hline 7 & & $59-64.5$ & 5.35 & - & - \\
\hline 8 & & $60-68.5$ & 8.15 & - & - \\
\hline 9 & $59-80$ & $61.5-62.5$ & 1.00 & - & - \\
\hline 10 & & $63.5-66$ & 2.25 & - & - \\
\hline 11 & & $68-74.5$ & 6.20 & $75.5-80$ & 4.35 \\
\hline 12 & $76-110$ & - & - & $76.5-90.5$ & 14.00 \\
\hline 13 & $79-93$ & $79-92$ & 13.15 & - & - \\
\hline 14 & $80-105.5$ & $84.5-86$ & 1.30 & $\therefore$ & - \\
\hline 15 & $81-104$ & - & - & $81-103.5$ & 22.35 \\
\hline 16 & $81-121$ & $81.5-88$ & 6.40 & $88-98$ & 10.00 \\
\hline 17 & $82-83.5$ & $82-83$ & 1.00 & - & - \\
\hline 18 & $84-96$ & $84-93$ & 9.00 & - & - \\
\hline 19 & $84-107$ & $84-87$ & 3.10 & $87.5-98$ & 10.25 \\
\hline 20 & & $98.5-102$ & 3.35 & - & - \\
\hline 21 & $94-111$ & - . & - & $103-106$ & 3.00 \\
\hline 22 & & $106.5-110$ & 3.20 & - & - \\
\hline 23 & $97-101.5$ & - & - & $97-101.5$ & 4.25 \\
\hline
\end{tabular}

Note: This table identifies individual axons whose growth cones and/or arbors were videorecorded by numbers 1 to 23 (first column). The second column [expressed in developmental age (h PF)] indicates the onset and termination of the videorecordings for each embryo, and the third column shows the developmental periods (h PF) during which growth cone progression for this study was monitored. The fourth column shows the lengths (in $\mathrm{h}$ and $\mathrm{min}$ ) of relevant scenes. The fifth and sixth columns list the developmental periods ( $\mathrm{h}$ PF) and their length ( $\mathrm{h}$ and $\mathrm{min}$ ), respectively, for data collection of terminal arbor formation (such as branch emission/retraction). The embryos received $\mathrm{DiO}$ between 33 and $61 \mathrm{~h} \mathrm{PF}$.

axes of the arbors were measured at the end of a recording session.

\section{RESULTS}

\section{Pulsatory and Exploratory Growth of Retinal Growth Cones under TTX-Induced Neural Impulse Blockade}

The elongation of DiO-labeled growth cones ( 4 from temporal, 13 from nasal retina, and 2 from ventral retina) of TTX-blocked axons was monitored in the tectum of zebrafish embryos between 52 and $111 \mathrm{~h}$ PF (Table 1). Their mode of growth was compared to 15 growth cones in normal, active embryos of our earlier study (Kaethner and Stuermer, 1992) to determine whether the intermittent elongation, periodic changes in morphol- ogy, and, in particular, the exploratory behavior of growth cones require a normal neural activity pattern. Growth cones were observed and filmed with $100 \times$ oil immersion lenses. The video system described in Methods allows the discrimination of lamellipodia and filopodia which are known to be less than $1 \mu \mathrm{m}$ in diameter on both growth cones and terminal arbors.

As in normal embryos, growth cones in the tectum of TTX-injected embryos grew in their typical stop-and-go-mode. This is exemplified in Figure 1 by a growth cone from the nasal retina, which is progressing from the central into the caudal tectum (axon no. 18 in Table 1). Growth cones enlarged and became complex during their "stop" phase. They extended lamellipodia and filopodia and thus explored their local environment much like growth cones of active axons. These exploratory periods, determined over 93 cycles, lasted from 4.5 to 325 

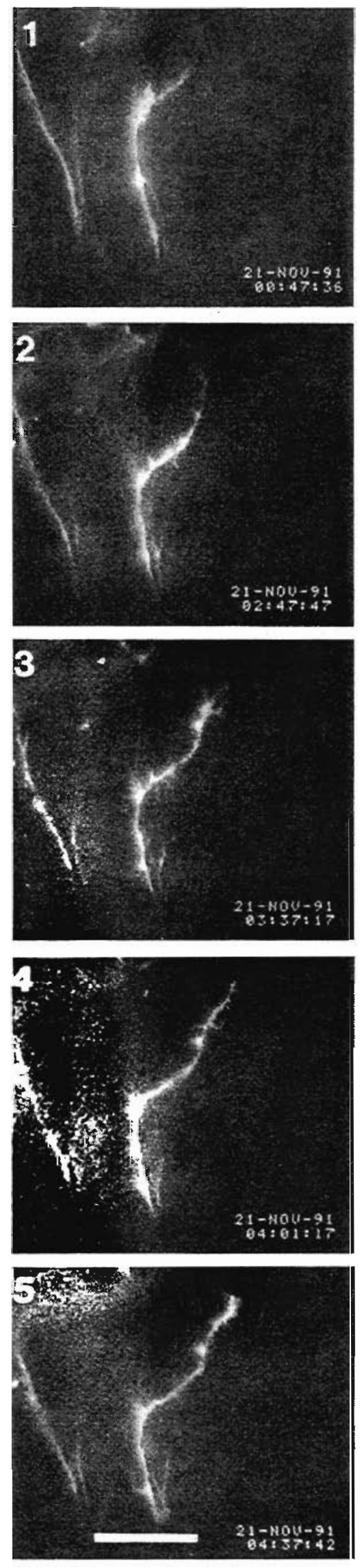

min and thus were of a similar range of duration as in normal embryos (Kaethner and Stuermer, 1992). In go phases, TTX growth cones acquired a streamlined morphology and projected a long filopodium that was, as in normal embryos, generally directed toward the target.

During the "go" phase, the extension of this long filopodium (ending with its arrival in the new location to which the growth cone followed) occurred with an average velocity of $183 \mu \mathrm{m} / \mathrm{h}$ (S.D., $\pm 138 \mu \mathrm{m} / \mathrm{h}$ ), but the velocity varied from growth cone to growth cone and also varied for individual growth from one "go" phase to another. This compares to the average filopodial velocity of $110 \mu \mathrm{m} /$ h (S.D., $\pm 85 \mu \mathrm{m} / \mathrm{h}$ ) of normally active axons where similar variations were observed! The difference in average filopodial velocity between TTX and normal growth cones was not statistically significant (U-test). The reason for the seemingly faster average velocity of filopodia of TTX growth cones lies in the fact that our ability to identify the emerging filopodium at the end of the "stop" phase has improved compared to our earlier study. However, the duration of a single "go" and "stop" phase, that is, a cycle, was in the same range for TTX-blocked and normally active axons. To determine the average growth velocity, we added the duration of stop and go phases of each of the 17 growth cones, measured the distances that they covered, and calculated the growth velocity of individual growth cones and the average of the group. Two growth cones (axons nos. 1 and 17 in Table 1 ) were not taken into account since each was observed only over one cycle. The average growth velocity of growth cones of TTX-blocked axons was $13 \mu \mathrm{m} / \mathrm{h}$ (S.D., $\pm 9 \mu \mathrm{m} / \mathrm{h}$ ) and $11 \mu \mathrm{m} / \mathrm{h}$ (S.D., \pm 3 $\mu \mathrm{m} / \mathrm{h}$ ) for normal axons (Kaethner and Stuermer, 1992). The average growth velocity of individual growth cones varied as demonstrated in Figure 2. Most TTX growth cones exhibited growth veloci-

Figure 1 Selected frames (images 1-5) from a 4-h observation period showing the periodic changes in morphology of a TTX-blocked growth cone (identified as no. 18 in Table 1 ) advancing in the typical stop-and-go mode. Images 1, 3, 5: During the "stop" phases, the growth cone is broadened and extends filopodia and lamellipodia but does not advance. The duration of the three "stop" phases were $4.5 \mathrm{~h}, 25 \mathrm{~min}$, and $2.5 \mathrm{~h}$. Images 2 and 4: The growth cone becomes streamlined when it follows the long filopodium that is emitted during "go" phases. Scale bar $=20 \mu \mathrm{m}$. In this and Figures 2 and 3 , the numbers in the lower-right corner indicate the date and time of each frame. 


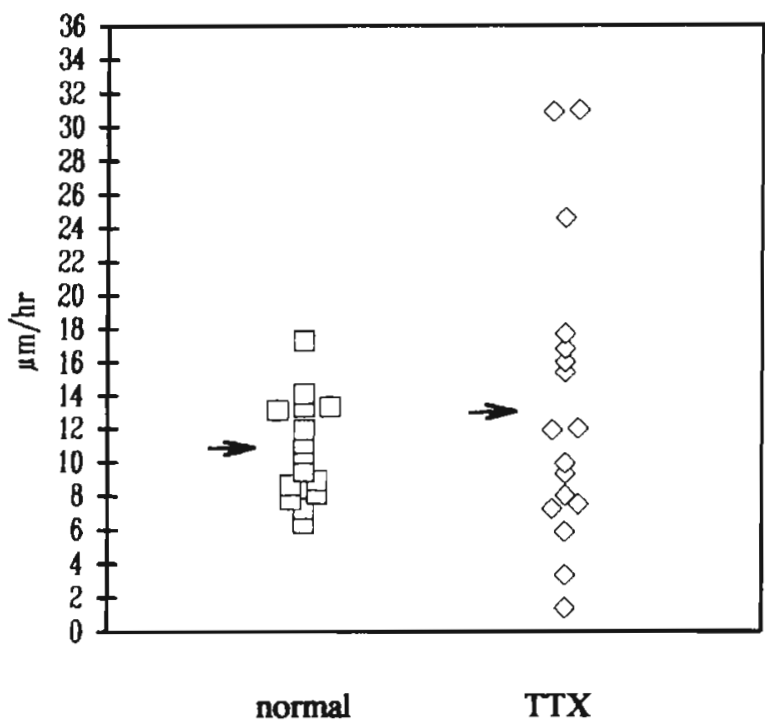

Figure 2 Comparison of the average growth velocities in (micrometers per hour) (ordinate) of TTX-blocked (diamonds, $n=17$ ) and normal axons (squares, $n=15$ ). The average of each group (TTX, normal, ) is marked by arrows.

ties similar to those of normal growth cones (between 6 and $18 \mu \mathrm{m} / \mathrm{h}$ ). But two TTX-growth cones grew more slowly and three did so at a faster rate. Whether the higher-and lower-growth velocities are caused by TTX cannot be determined from the data pool available here. The difference in average growth velocities between the TTX and the control group, however, was not statistically significant (U-test). More important, however, TTX-induced impulse blockade does not affect the exploratory behavior of growth cones in rest phases or the target-directed advancement in go phases.

One exception was a growth cone which was target-directed but advanced smoothly and steadily with ruffling lamellipodia throughout its growth. But smoothly progressing growth cones were also noted occasionally in normally active embryos, indicating that the pulsatory growth is typical but not mandatory (Kaethner and Stuermer, 1992).

TTX-blocked axons and normal, active axons almost always grew directly towards their retinotopic target sites. Occasionally, a growth cone extended its long filopodium in a nontarget direction and followed it. But this was followed by the retraction of the growth cone from the errant position, a new phase of active exploration, and formation of a new long filopodium that was target directed. Left behind was a small side branch which either persisted for hours or was rapidly retracted (Kaethner and Stuermer, 1992). Such deviations from the target-oriented growth were for TTX axons as rare as that for normal axons. TTX-induced neural impulse blockade, therefore, does not increase the formation of stable or transient side branches.

\section{Dynamics of Arbor Formation}

Like growth cones of active axons, growth cones of TTX-blocked axons ceased to elongate when they reached their retinotopic target territory and began to branch (Fig. 3). This applied to all temporal axons when they arrived at their target territory in the rostral tectum, to nasal axons when they arrived at their target sites in the caudal tectum, and to ventral axons meeting their home tertitory in the dorsal tectum.

Figure 3 exemplifies in a series of selected images from a 34-h continuous observation period the typical and highly dynamic events of arbor formation in a TTX-injected embryo (axon no. 12 in Table 1). This axon was stained through insertion of the DiO crystal in the ventro-temporal retina near the optic disc. Its growth cone (Fig. 3) ceased to progress after arriving at its retinotopic target territory in the dorso-rostral tectum close to the boundary between the rostral and caudal tectal halves (Fig. 5). The growth cone first emits only a few branches (Fig. 3) of which two persist and one disappears. During the next $5 \mathrm{~h}$, one primary branch adds secondary and tertiary branches (images 1 and 2 in Fig. 4). The other primary branch gains in length and also emits higher-order branches (image 1 in Fig. 4). With time, some of the initially formed branches and those added later are retracted, as indicated in Figure 4 (images 2, 5, 7 , and 18). New branches emerge proximal to the first formed branches and one example is seen in Figure 4 (image 12). This branch in fact persisted to the end of the observation period. One of the early formed branches and one of the later emerging ones join and form a circular arbor structure (Fig. 4; images 19-28).

Some branches elongated with prominent growth cone-like structures at their tips [Fig. 4 (images 12 and 18)], but others emerged and elongated without such a growth cone [ Fig. 4 (images 1-6)]. All branches, however, remained confined to an almost circular area, the exploration field. The total area explored by this arbor is shown in Figure 5. The dimension of the exploration field of this and further arbors ( see below) was determined in two ways as explained in Methods. In the first method, the tips of the branches were encircled by 

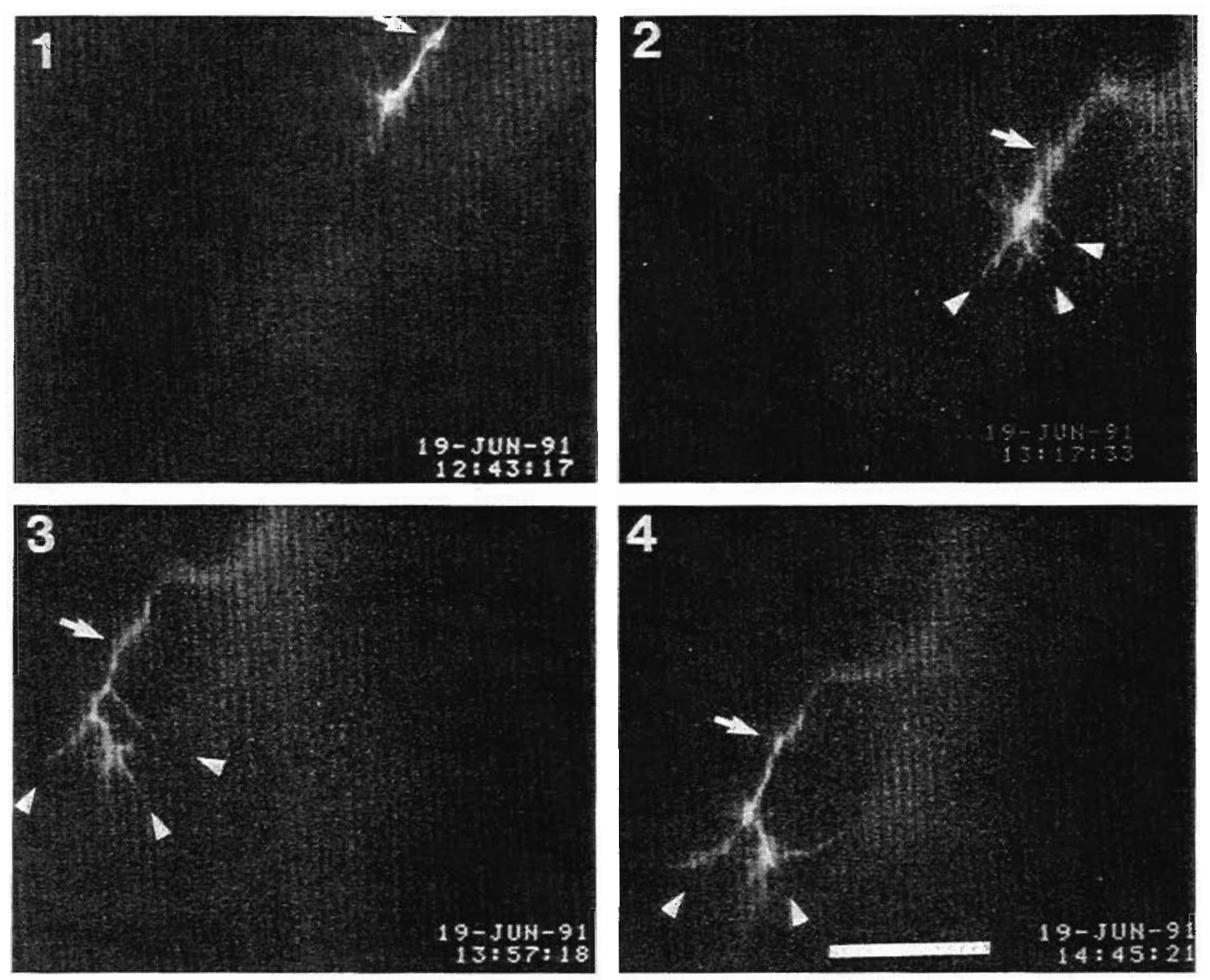

Figure 3 Selected frames (images 1-4) from a 2-h observation period showing the growth cone of a TTX-blocked axon (identified as no. 12 in Table 1) arriving at its retinotopic target site. The growth cones halts (image 1) and projects 3 branches (arrowheads in images 2, 3). Two branches persist, and one is retracted (image 4). The further development of the arbor is shown in Figure 3. The arrows mark a reference point on the axon proximal to the growth cone (see also Fig. 3, images 1 and 28). Scale bar $=20 \mu \mathrm{m}$.

a line. The long and short axes of the elliptical feature were $52.6 \times 40.0 \mu \mathrm{m}$, respectively, and the area of the tectal neuropil covered by the exploration field was $7.1 \%$. The alternate method for determining the exploration field was to add up grid squares that were touched by transient and permanent branches. Using this method, we note the exploration field comprised $4.5 \%$ of the neuropil area.

Since we were able to observe individual developing arbors in TTX-injected embryos over longer periods than that done previously in normal embryos (Kaethner and Stuermer, 1992) simply because the TTX-injected embryos survived longer, we could confirm the impression that the forming arbors are most active during the first 13-20 h after the growth cone has begun to branch. Thereafter, movement of processes is restricted to the very tips of the branches that consolidated over the foregoing hours. To determine the number of branches emitted and retracted by a developing arbor of TTX-blocked axons during its most active branching phase, emerging and receding branches were counted over this period and compared to arbors of normal embryos.

During 14 hours after onset of branching, the arbor of Figures 3 and 4 extended 38 branches and retracted 28. The longest observation period for a developing normal arbor (Kaethner and Stuermer, 1992 ) was $13 \mathrm{~h}$. This normal arbor already had 8 branches when we began monitoring it, and extended 20 and retracted 20 branches over the sub- 

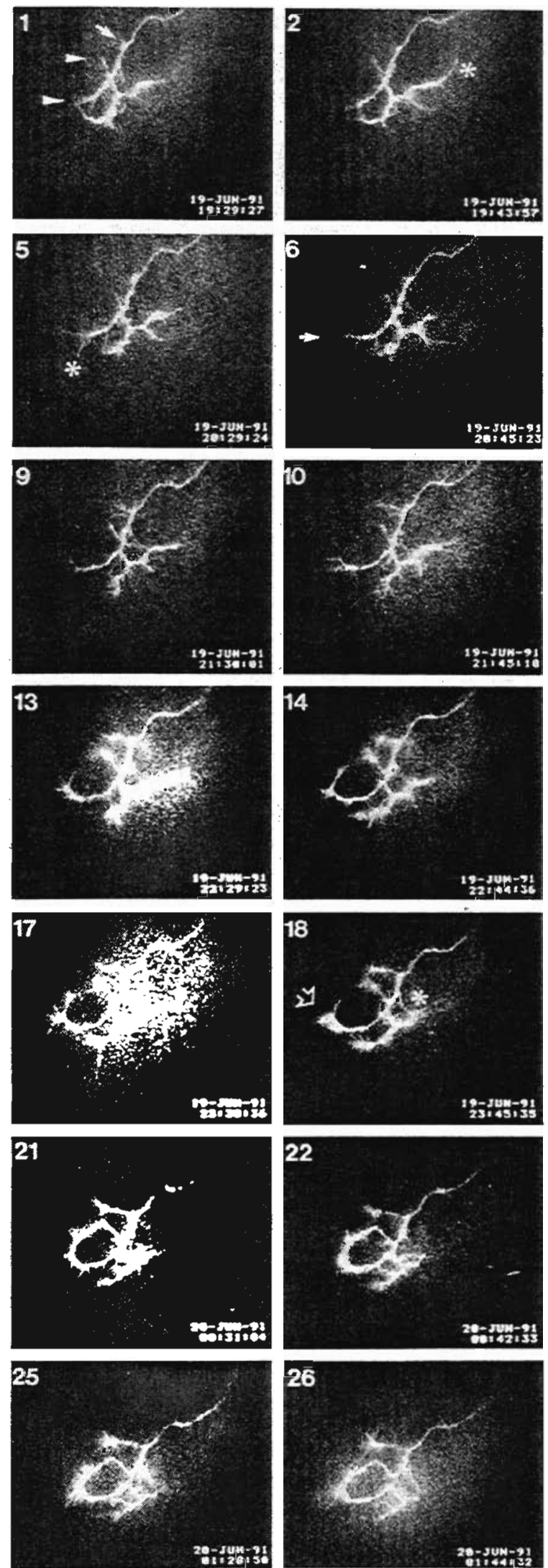
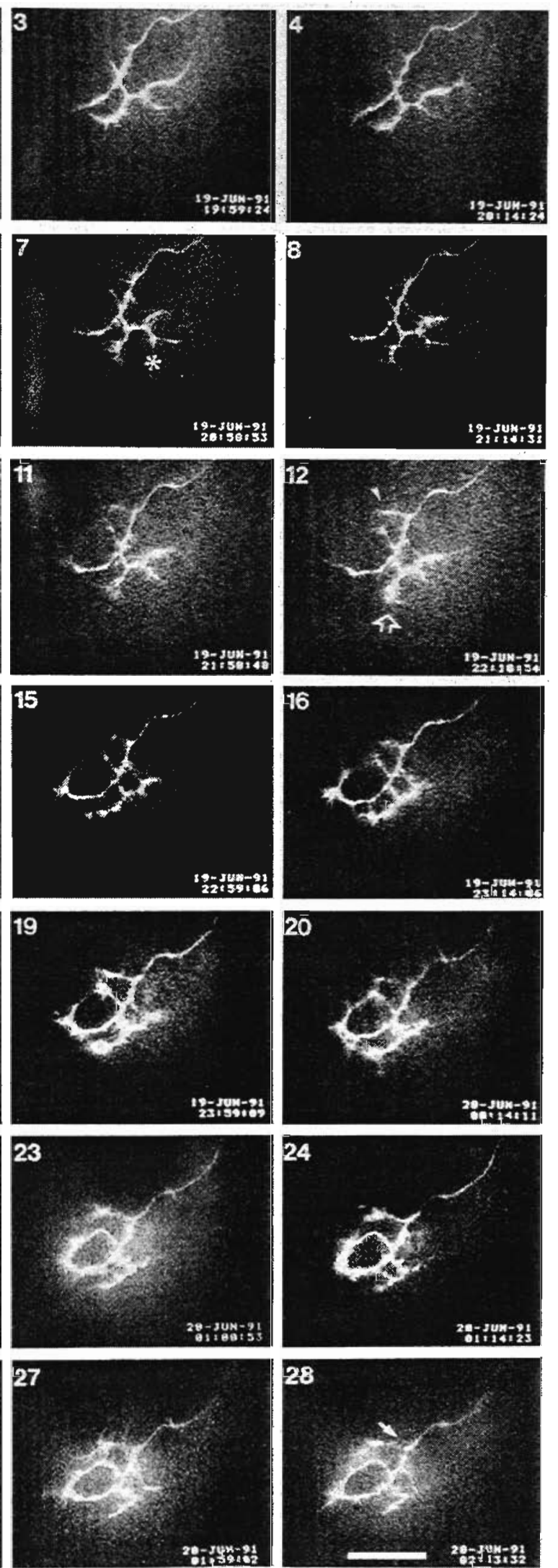
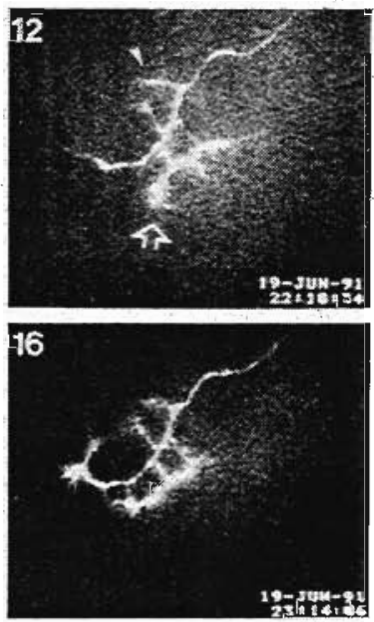

20
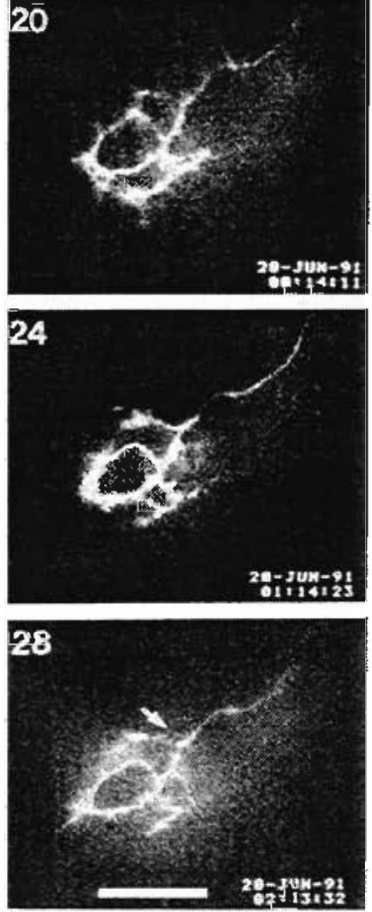

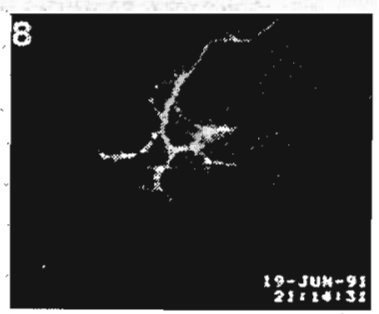


sequent hours. Per hour, 2.7 branches arose and 2.0 retracted on the TTX arbor. The behavior of this arbor is typical and arbor formation of 6 additional TTX-blocked axons was similar. The number of branches emitted and retracted by each arbor and the ratio between the two is listed in Table 2. On the average, TTX arbors extended 3.1 (S.D., \pm 0.6 ) branches and retracted 1.9 (S.D., \pm 0.7 ) branches per hour with a ratio of 1.7 (S.D., \pm 0.4 ) (Table 1). Arbors from normal active axons emit an average of 2.6 (S.D., \pm 1.0 ) branches and retract 1.6 (S.D., \pm 0.6 ) branches per hour and have an emission to retraction ratio of 1.7 (S.D., \pm 0.7 ) (Kaethner and Stuermer, 1992).

These data indicate that there is no significant difference in branch appearance and recession between normal arbors and those developing under TTX-induced impulse blockade (U-test). Nor were branches of arbors in TTX-injected embryos longer than those in normal embryos. This is reflected in the dimension of the terminal arbors' exploration fields. The long and short axes of the exploration fields of 7 TTX-blocked arbors are listed in Table 2 and were compared to 8 normal arbors. On the average, the exploration field has a long axis of $38.4 \mu \mathrm{m}$ (S.D., $\pm 15.9 \mu \mathrm{m}$ ) and a short axis of $41.3 \mu \mathrm{m}$ (S.D., $\pm 25.6 \mu \mathrm{m}$ ) for TTX arbors, and $38.1 \mu \mathrm{m}$ (S.D., $\pm 9.1 \mu \mathrm{m}$ ) and $38.8 \mu \mathrm{m}$ (S.D., \pm 16.7 $\mu \mathrm{m})$ for normal arbors. By the first method of determining the dimension of the exploration fields, those of TTX arbors (Table 2) comprised 1.1\%$11.6 \%$ of the surface area of the tectal neuropil, and those of normal axons $1.9 \%-11.0 \%$. The exploration fields determined by the second method, that is, by counting grid squares touched by branches (see Methods and above), comprise $1.0 \%-7.4 \%$ of the surface area of the tectal neuropil for TTX arbors (Table 2), and 1.0\%-5.3\% for normal arbors.

The areas determined by the latter method depend on the time over which the forming arbor was observed, because the longer we can monitor them in their active branching phase the more branches are seen appearing and disappearing. Since we observed the TTX arbor development over longer time periods than normal arbors, we normalized the areal values to a $1-\mathrm{h}$ observation period. This value was set in relation to the area covered by the final arbor at the end of the observation periods to determine the areal increase per hour. The areal increase for the exploration fields of TTX arbors after the 1-h observation period is listed in Table 2 and is on average $29.2 \%$ (S.D., $\pm 8.6 \%$ ) of the arbor size and $27.3 \%$ (S.D., $\pm 7.1 \%$ ) for normal arbors. According to statistical tests (U-test), there is no significant difference between these values. Thus, activity-deprived axons explore a tectal field that is no larger than the exploration field of active axons.

\section{Terminal Arbors}

The purpose of this study is to evaluate the dynamics of axon growth and terminal arbor formation. An evaluation of the sizes of terminal arbors and their relation to the tectal surface area for both normal and TTX-blocked axons was performed previously in a significant number of embryos (Stuermer, 1988; Stuermer et al., 1990). For the small number of arbors whose development was filmed here, we examined whether they fall into the previously established size categories.

The sizes of terminal arbors were determined at the end of the observation period by focusing through the whole extent of the arbor and copying it from the screen. The tips of the branches were connected by a line and the long and short axes of the elliptical feature measured (Stuermer, 1984). The long and short axes of normal and TTXblocked arbors are listed in Table 3. The sizes of terminal arbors and thus the lengths of their axes vary. This variance is found in adults (Stuermer,

Figure 4 A series of photomicrographs (images 1-28) of $7 \mathrm{~h}$ from a time-lapse movie of $34 \mathrm{~h}$ duration, documenting the typical structural changes during arbor elaboration. This arbor (identified as no. 12 in Table 1) develops under TTX-induced neural impulse blockade and derives from the growth cone in Figure 3. Arrows in images 1 and 28 demarcate, as in Figure 3, a reference point on the axon. Of the first branches, formed by the growth cone (Fig. 3), two persisted and made secondary branches (images 1,2), the other branch of Figure 3 was retracted. One of the persisting branches and a newly emerging one (arrowheads in image 1) grew considerably in length. Branches marked by an asterisk in images $2,5,7$, and 18 , were also retracted and, therefore, no longer visible in later images $(7,9,21$, and 27 , respectively). The open arrows in images 12 and 18 point to growth cones at the tips of elongating branches and the small arrow in image 6 to a branch growing in length without a typical growth cone. A small arrowhead in image 12 indicates a new branch formed proximal to the earlier ones. Scale bar $=20 \mu \mathrm{m}$. 


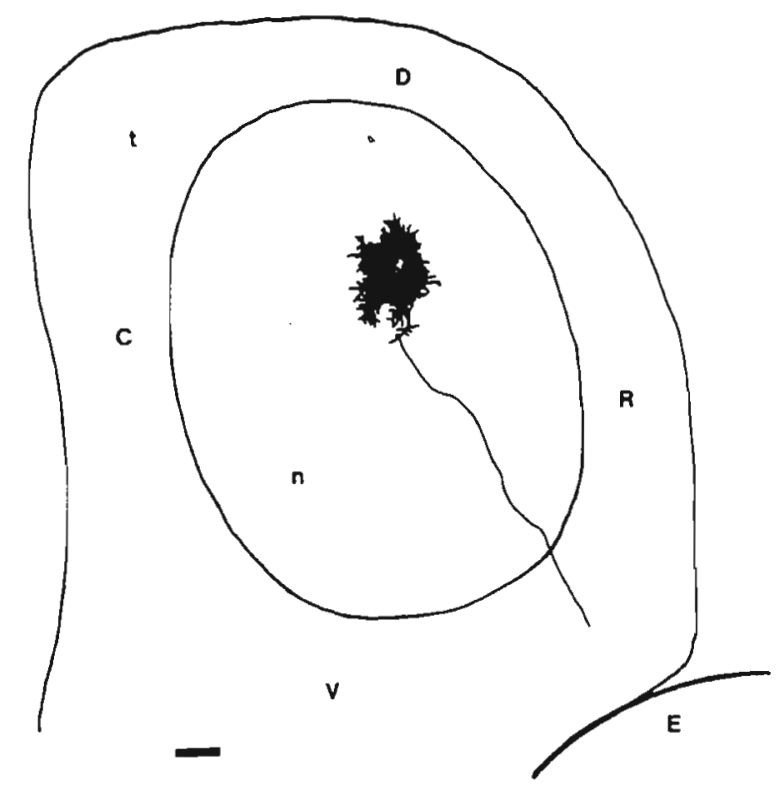

Figure 5 Outline of the boundaries of the zebrafish tectum and its neuropil. The path of the ventrotemporal TTX-blocked axon, whose terminal arbor development is documented in Figures 3 and 4, is shown by the black line. The blackened area represents the exploration field of the developing arbor. The area of the exploration field comprises $4.5 \%$ of the tectal neuropil area. $C=$ caudal; $D$ $=$ dorsal; $\mathrm{E}=$ eye $\mathrm{n}=$ neuropil; $\mathrm{R}=$ rostral; $\mathrm{t}=$ tectum; $\mathrm{V}=$ ventral. Scale bar $=20 \mu \mathrm{m}$.

1984; Schmidt et al., 1988) as well as in embryos (Stuermer and Raymond, 1989; Kaethner and Stuermer, 1992; Schmidt and Buzzard, 1993).
TTX arbors had long axes of $30.2 \mu \mathrm{m}$ (S.D., $\pm 23.6 \mu \mathrm{m})$ and short axes of $23.6 \mu \mathrm{m}$ (S.D., \pm 6 $\mu \mathrm{m}$ ). Those of normal arbors were $32.3 \mu \mathrm{m}$ (S.D., $\pm 11.5 \mu \mathrm{m}$ ) and $29.9 \mu \mathrm{m}$ (S.D., $\pm 17.9 \mu \mathrm{m})$, respectively. The areas of tectum that they occupied were $0.9 \%-5.5 \%$ of tectum for TTX and $1.1 \%-6.0 \%$ for normal arbors according to the first method (that is, encircling the tips of branches), and $0.5 \%-1.3 \%$ for TTX (Table 3 ) and $0.7 \%-1.4 \%$ for normal arbors according to the second method (that is, adding squares occupied by branches). Thus, the TTX arbors observed here fell into the size ranges of TTX arbors in the earlier report (Stuermer et al., 1990). Consistent with our earlier findings on fixed brains (Stuermer et al., 1990), TTX arbors are, therefore, no larger than normal arbors. The areal values of the arbors (Table 3 ) were set into relation to the areal values of their exploration fields (Table 2) (Kaethner and Stuermer, 1992). The exploration fields were 1.2-5.1 times larger (Table 3 ) than the terminal arbor area according to the first method (encircling the tips of the branches). With the second method which we consider as the more appropriate one for the size determination of the exploration field, the latter was 2.0-5.6 times larger (Table 3) than the arbor area. Thus, the arbors observed here occupy on the average 2.3 (first method) and 3.7 times (second method) smaller territory of tectum than their exploration fields.

One terminal arbor of abnormal appearance was noted, although its formation was not ob-

Table 2 Exploration Field

\begin{tabular}{|c|c|c|c|c|c|c|c|}
\hline $\begin{array}{l}\text { Exploration } \\
\text { Field }\end{array}$ & 1 & 2 & 3 & 4 & 5 & 6 & 7 \\
\hline $\begin{array}{l}\text { Branch formation } \\
\text { (no. h) }\end{array}$ & 2.7 & 3.9 & 3.5 & 2.2 & 3.4 & 3.0 & 3.1 \\
\hline $\begin{array}{l}\text { Branch elimination } \\
\text { (no. h) }\end{array}$ & 2.0 & 2.7 & 2.6 & 1.1 & 2.4 & 1.3 & 1.5 \\
\hline $\begin{array}{l}\text { Ratio formation/ } \\
\text { elimination }\end{array}$ & 1.4 & 1.4 & 1.3 & 2 & 1.4 & 2.3 & 2.1 \\
\hline $\begin{array}{l}\text { Long axis } \times \\
\text { short axis } \\
(\mu \mathrm{m})\end{array}$ & $52.6 \times 40.0$ & $29.3 \times 25.3$ & $38.7 \times 66.0$ & $35.3 \times 39.3$ & $93.3 \times 50.0$ & $18.7 \times 20.0$ & $21.3 \times 28.0$ \\
\hline $\begin{array}{l}\text { Area (ellipse) } \\
(\% \text { tectum) }\end{array}$ & 7.1 & 1.9 & 7.1 & 4.2 & 11.6 & 1.1 & 2.0 \\
\hline $\begin{array}{l}\text { Area (squares) } \\
\text { (\% tectum) }\end{array}$ & 4.5 & 1.4 & 3.9 & 3.5 & 7.4 & 1.0 & 1.5 \\
\hline $\begin{array}{l}\text { Areal increase } \\
(\% \text { arbor } / \mathrm{h})\end{array}$ & 34.5 & 44.8 & 29.6 & 21.1 & 20.4 & 30.1 & 24.0 \\
\hline
\end{tabular}

Note: A list of typical parameters during the formation of terminal arbors $(n=7)$ under TTX-induced neural impulse blockade. The area of the exploration field is expressed as a percentage of the tectal neuropil area. 
Table 3 Arbors

\begin{tabular}{cccccccc}
\hline Arbor & 1 & 2 & 3 & 4 & 5 & 6 & 7 \\
\hline $\begin{array}{c}\text { Long axis } \times \\
\text { short axis } \\
(\mu \mathrm{m})\end{array}$ & $34.7 \times 23.7$ & $24.7 \times 15.3$ & $18.7 \times 27.3$ & $32.7 \times 26.7$ & $65.3 \times 33.3$ & $15.3 \times 18.7$ & $20.0 \times 21.3$ \\
$\begin{array}{c}\text { Area (ellips) } \\
\quad(\% \text { tectum) }\end{array}$ & 2.7 & 1.0 & 1.4 & 2.7 & 5.5 & 0.9 & 1.4 \\
$\begin{array}{c}\text { Area (squares) } \\
\quad(\% \text { tectum) }\end{array}$ & 0.9 & 0.6 & 0.7 & 1.0 & 1.3 & 0.5 & 0.7 \\
$\begin{array}{c}\text { Ratio EF/arbor } \\
\quad(\text { ellipse) }\end{array}$ & 2.6 & 1.9 & 5.1 & 1.6 & 2.1 & 1.2 & 1.4 \\
$\begin{array}{c}\text { Ratio EF/arbor } \\
\text { (squares) }\end{array}$ & 5.0 & 2.3 & 5.6 & 3.5 & 5.7 & 2.0 & 2.1 \\
\hline
\end{tabular}

Note: Sizes of 7 terminal arbors that developed under TTX-induced neural impulse blockade, determined at the end of the live observation of their development. The area they cover is expressed as a percentage of the tectal neuropil area. EF = exploration field.

served. The temporal axon had a few side branches over the retinotopic target field but also another long process that had grown for $12 \mu \mathrm{m}$ past the target site. This process curved back with numerous side branches next to the other side branches proximal to the curved path. The axon may have grown beyond its target site after it had extended a few branches, corrected its course, and then branched more extensively over its correct target area. This observation implies that axons are capable of correcting mistakes in the absence of normal spike activity (Hartlieb and Stuermer, 1987). This transient aberration of the axon was probably not caused by the TTX-induced impulse blockade, since occasional abnormalities were also seen in normal embryos. As was the case for the curved branch of an arbor. most of the abnormal axons were observed too late for time-lapse recordings. Further abnormalities consisted of axons overshooting their retinotopic target territory, where companion axons ceased to grow and arborized. In some instances. the errant axons exhibited a beaded appearance and no growth cone, indicating that they degenerated. Others continued their growth and escaped further observation. An estimate on the frequency of such mistakes was obtained by companng the trajectories of 190 axons in normal embryos to 270 axons in TTX embryos. They amounted to roughly $1 \%$ ( 2 of 190 ) in normal and to roughly $1 \%$ ( 3 of 270 ) in TTX embryos.

\section{DISCUSSION}

Examination of live growing retinal axons in the zebrafish tectum have recently revealed a previously unobserved exploratory growth behavior of both the growth cone and the developing terminal arbor (Kaethner and Stuermer, 1992). In the foregoing experiments, the growth behavior of activitydeprived axons were analyzed with time-lapse video microscopy to determine whether these exploratory phases of axon growth involve neural activity-dependent communication of the developing axons with the tectum. This was of particular interest in light of findings that the establishment of an orderly visual projection depends on normal neural activity patterns in most vertebrate species but apparently not in zebrafish embryos (reviewed in Goodman and Shatz, 1993). The present experiments are, therefore, a refinement of a previous investigation in which the trajectories and terminal arbors of groups of TTX-blocked axons in fixed zebrafish brains were examined (Stuermer et al., 1990). The results demonstrate that all growth phases of axons through the tectum including the dynamics of terminal arbor formation at retinotopic target sites proceed in zebrafish embryos normally under TTX-induced neural impulse blockade.

We demonstrated in our earlier study that a single injection of TTX into 30- to 38-h-old embryos blocks neural activity of retinal axons and evoked potentials that normally can be readily recorded from the tectum of embryos $70 \mathrm{~h} \mathrm{PF}$ and older (Stuermer et al., 1990). Moreover, electrical activity of tectal layers deeper than the retinal terminal arbor layers and from brain centers below the tectum in normal embryos was silenced by TTX, as is the activity of motoneurons. There is also a close correlation between recovery of twitching (the typical reflex of fish embryos that occurs spontaneously and reliably upon touch ) and the recovery of electrical activity in the fish brain. In the present 
study, we, therefore, monitored axon growth only in paralyzed embryos and discarded those that moved. Movement resulting from recovery from the TTX blockade was easily recognized on the microscope stage because embryos were only anesthetized by TTX for these experiments.

The advance of growth cones in the zebrafish tectum is punctuated by "stop" periods (Kaethner and Stuermer, 1992) during which the growth cones do not advance but are enlarged and appear to be quite active. They appear to explore their local environment by extending lamellipodia and filopodia in all directions. During this phase, they probably contact a number of tectal cells and this interaction may direct the subsequent activity of the growth cone. The exploratory phases are typically followed by projection of the filopodium and growth cone advancement in the direction of the target. Our present results with activity-blocked axons show that the interaction of the retinal growth cones with the tectum, the determination of retinotopically appropriate and inappropriate tectal areas, and the command to advance or to explore does not require $\mathrm{Na}$-dependent neural activity: the behavior of TTX-blocked axons does not differ from that of normal axons.

It should be emphasized that the exploratory behavior of growth cones analyzed in this study occurs within the target area, that is, the optic tectum. This differs from axonal pathfinding outside the target, that is, the growth through the optic nerve and tract (Harris, 1984), which is known to be correctly accomplished in the absence of neural activity in various species (reviewed in Goodman and Shatz, 1993). However, when axons have arrived at their target centers, they interact in most vertebrate species with the target cells in a way that does require the neural activity-driven communication with the target.

As it is known that growth cones are capable of making synapses (Reh and Constantine-Paton, 1985; Scalia and Matsumoto, 1985), we considered the possibility that zebrafish retinal growth cones employ an activity-driven mechanism for axon-target communication during their intratectal growth. Dendrites of tectal cells are developing during the time in which the axons progress through the tectum (R. J. Kaethner and C. O. Stuermer, unpublished observations) and are available as synaptic partners. Moreover, regenerating retinal axons in the adult goldfish have been shown to form synapses as soon as they enter the tectum (Stuermer and Easter, 1984) and form synaptic contacts, although transiently, with retinotopically inappropriate cells. Whether zebrafish retinal growth cones do, in fact, establish synapses during their exploratory phase has not yet been determined. However, the present experiments have shown that activity blockade does not result in any noticeable disturbance of growth cone behavior or target-directed intratectal navigation. We, therefore, conclude that activity-driven interactions of developing zebrafish axons is not necessary for target approach and recognition.

The second striking phase of exploratory growth begins once the axons arrive at their retinotopic target sites, where extension and retraction of side branches begins and continues for hours. Comparison of the rate of branch extension and retraction by normal and TTX-blocked axons shows that activity blockade does not affect this parameter of arbor formation. If forming arbors of TTXblocked axons sent transient branches into distant tectum, then we could have missed those in our earlier analysis of fixed brains but we would have seen them here by direct observation. There were no such abnormal, long, transient branches, nor did the number of branches of TTX-blocked axons exceed that of normal axons. This is also reflected by the sizes of the exploration fields. The radii and circumferences of the exploration fields under TTX were no larger than those in controls. That TTX-induced neural impulse blockade does not increase the total number of branches extended and retracted was shown by the ratio of branch extension/retraction per hour, by the area of the exploration field, and by its rate of increase.

The growth and orientation of the developing axons and arbors is horizontal with respect to the surface of the tectum (Stuermer, 1984). This is of great advantage for filming their growth (Kaethner and Stuermer, 1992) because the growth cones and most of the extent of their arbors can be kept in focus. However, possible dynamic changes of arbor processes below the plane of focus may still be missed. Several developing arbors were, therefore, examined by repeatedly focusing through the entire extent to determine if they project processes deeper into tectal layers. All arbors were likewise examined at the end of the recording session. The vast majority of branches indeed lie parallel to the tectal surface, so that we are confident to have observed most of the characteristic growth-related changes of both TTX-blocked and normal axons.

Since it was possible to observe the forming arbors of TTX-blocked axons over long periods, we can also exclude the possibility that TTX-blocked axons continue to branch extensively when normal 
arbors consolidate their branches. Instead, TTXblocked arbors stabilized branches after a 14- to 20-h exploratory phase following the onset of branching and thereafter confined the turnover of processes to the very tips of the branches. A similar phenomenon was observed in a normal arbor, which was continuously filmed for $13 \mathrm{~h}$ (Kaethner and Stumerer, 1992). It consolidated its branches - except for the tips-towards the end of the observation period. It was also seen in elaborate and thus more mature arbors, which exhibited movement of fine processes only at the tips of the branches. Incidentally, the TTX arbors that were here observed over extended periods (up to $34 \mathrm{~h}$ ) confirm our earlier impression that extension and retraction of major branches is limited in time, and that these events lead to the emergence of a typical terminal arbor. These conclusions are based on a small sample of axons whose behavior was recorded at length. That they are typical is confirmed by analyses of groups of axons and their arbors in this and the earlier study. Abnormal trajectories and an abnormal pattern of side branch arrangement are rare. However, occasional mistakeswhich are often, but not always, corrected-appear to be natural imperfections during the formation of the nervous system (for instance, Harris et al., 1987), and for retinal axons in the zebrafish tectum are estimated to amount to $1 \%$ for both TTX and normal embryos. The curving branch of the TTX-blocked arbor described in this study is significant in so far as this observation suggests that axons do not need their normal activity patterns for such corrections. A study on regenerating retinal axons in adult goldfish came to the same conclusion (Hartlieb and Stuermer, 1987).

The major goal of this study was to analyze the dynamics of terminal arbor elaboration and test whether the behavior of TTX axons would differ from that of normal axons. We measured the sizes of the terminal arbors whose development was filmed to test whether they fell into the range of dimensions determined earlier for TTX as well as normal arbors in a large number of animals (Stuermer, 1988; Stuermer et al., 1990). Our present data, therefore, were not aimed at a statistical evaluation of arbor sizes, because this had been done before. The terminal arbors of TTX-injected embryos at the end of the observation period were similar in size to those of normal embryos and were, in fact, of similar dimensions as those measured in fixed embryos in earlier studies (Stuermer, 1988; Stuermer et al., 1990; Kaethner and Stuermer, 1992). Since arbors of TTX-blocked axons developed over retinotopically appropriate domains, the present study confirms the conclusion of our earlier reports (Stuermer et al., 1990). Zebrafish retinal axons establish a precisely organized retinotopic map even in the absence of $\mathrm{Na}$ channel-dependent neural activity. The present time-lapse recordings revealed that this is achieved in a manner that is indistinguishable from axons with normal activity. Thus, in contrast to birds and mammals, the retinotopic map in zebrafish embryos forms directly and is independent of $\mathrm{Na}$ channel-dependent activity. There is no diffuse projection caused by extensive axonal branching over inappropriate tectal areas as occurs in chick tectum (Nakamura and O'Leary, 1989), rat colliculus ( Simon and O'Leary, 1990, 1992), and LGN of cats (Sretavan et al,, 1988), and thus the abolition of aberrant side branches (Kobayashi et al., 1990) is unnecessary in zebrafish embryos. In Xenopus embryos, the retinotectal projection develops differently from that in fish and involves the segregation of the initially overlapping projection of temporal and nasal arbors over the rostral tectum (O'Rourke and Fraser, 1990). However, the subsequent movement of nasal arbors into newly created caudal tectum also appears not to require $\mathrm{Na}$ channel-mediated activity (Harris, 1984).

In fact, zebrafish growth cone navigation as well as arbor formation at retinotopically defined sites (Stuermer, 1993) are entirely consistent with the theoretical predictions on growth cone behavior in fields of gradients of tectal markers (Gierer, 1987). Predictions are that growth cones "measure" at each position of their path through the tectum the actual concentration of the tectal marker molecules and compare that to their own positional markers which are defined by their retinal positional origin. Growth cones are thought to be capable of measuring differences of marker molecule concentration over their own extent, and activate those portions of the growth cone that perceive a marker molecule concentration that most clearly corresponds to the concentration of their own markers. The growth cone's exploratory behavior during "rest" phases may be the morphological correlation of its "measurement" of and interaction with the tectal marker. Emission of its long filopodium in the direction of the target might represent the result of this action. As long as they have not reached their tectal target sites, growth cones are predicted to advance and move in the direction of the target. The graded distribution of markers allows such an approach from any position. The theory further predicts that growth cones should 
stop and branch at tectal sites where the molecule concentration of tectal markers matches that of the growth cone. Branches should extend over an area in which the axon does not perceive concentration differences (Gierer, 1987). The onset of branch formation by zebrafish retinal axons at retinotopically appropriate sites and the extension of branches restricted to a small exploration field are also compatible with the above predictions. Thus, the existence of a precisely organized retinotopic map in zebrafish embryos is not the only evidence of a possible gradient of positional markers. The behavior of the growing axons observed here and in our earlier study (Kaethner and Stuermer, 1992 ) supports this view directly. Further support is provided by studies demonstrating the existence of a tectal guidance component in chick (Walter et al., 1987), mouse (Godement and Bonhoeffer, 1989), and fish (Vielmetter and Stuermer, 1989). This component is graded in its distribution (Walter et al., 1987) and retinal growth cones are capable of responding to concentrational differences of this molecule (Walter et al., 1987; Baier and Bonhoeffer, 1992).

The postembryonic development of the retinotectal projection in fish and frogs differs from the development of visual projections in higher vertebrates in that the retina and tectum continue to grow, throughout adulthood in goldfish (review: Easter, 1986; Raymond, 1986), at least until adulthood in zebrafish, and through metamorphosis in frogs. In fact, most neurons in the retina and tectum in goldfish and in zebrafish are born after the first retinotopic map is formed in the embryo (Easter et al., 1981; Schmidt and Buzzard, 1993; Stuermer, 1988; Laessing et al., in press). We have shown for zebrafish (Stuermer, 1988), as Sakaguchi and Murphey (1985) have for Xenopus, that the size of the individual terminal arbor increases with the growth of the tectum, but as in Xenopus (Sakaguchi and Murphey, 1985), the ratio of the area covered by an arbor to the area of tectum (tectal coverage) declines. Thus, the precision of the retinotectal map improves with age (Stuermer, 1988; Sakaguchi and Murphey, 1985), although the animal's vision already functions well without such improvements. A recent study suggests that disturbance of normal activity patterns in fish affects these later stages in the development of the fish retinotectal map (Schmidt and Buzzard, 1993). As demonstrated recently by Schmidt and Buzzard (1993), the receptive fields in 1.5- to 2year-old goldfish raised under strobe light were enlarged, and small and large arbors-but not me- dium sized ones-bore ectopic side branches. Terminal arbors in fish constantly move (Easter and Stuermer, 1984), while the retina and the tectum grow to maintain retinotopia, a process called shifting of terminal arbors (Reh and Constantine-Paton, 1984; Easter and Stuermer, 1984). It appears that normal activity patterns may be required during the process of retinotectal arbor shifting for the elimination of side branches (Schmidt and Buzzard, 1993). This may be also true of larval zebrafish until they have reached adulthood, since zebrafish retinae and tecta also enlarge and add neurons from embryonic stages through larval life into adulthood. Thus, the precision in lower vertebrates improves during postembryonic and larval development. In some, as in goldfish this improvement continues throughout life, and appears to depend to some extent on neural activity (Schmidt and Buzzard, 1993).

It is, however, remarkable that frogs and fish. rely on their early visual projection for catching prey and feeding soon after completion of embryogenesis. The map must be, therefore, precise enough to subserve such functions. Furthermore, in contrast to birds and mammals the improvement of the "grain" of the map in frogs and fish occurs in parallel with and is dependent on ongoing neurogenesis in the retina and tectum. In these respects this process differs from map refinement in embryonic birds and mammals. The gain for fish is that this process leads to the continuous improvement of visual acuity (Hairston et al., 1982).

This work was supported by a grant of the DFG, SFB 156 to C.A.O.S. The authors thank Mary Anne Cahill for reading and correcting the manuscript, Doris Bliestle and her coworkers for the photographic reproductions, and Martin Bastmeyer, Tobias Reisbeck, and Alexandra Haidekker for help during extended time-lapse recording sessions.

\section{REFERENCES}

BAIER, H. and BONHOEFFER, F. ( 1992). Axon guidance by gradients of a target-derived component. Science 255:472-475.

BONHOEFFER, F. and Glerer, A. (1984). How do retinal axons find their targets on the tectum. Trends Neurosci. 8:378-381.

Bovolenta, P. and Mason, C. (1987). Growth cone morphology varies with position in the developing mouse visual pathway from retina to first targets. $J$. Neurosci. 7:1447-1460.

Chien, C. -B., Rosenthal, D. E., Harris, W. A., and 
Holt, C. E. (1993). Navigational errors made by growth cones without filopodia in the embryonic Xenopus brain. Neuron 11:237-251.

EASTER, S. S. JR. (1986). Rules of retinotectal mapmaking. BioEssays 5:158-162.

EASTER, S. S. JR., RusofF, A. C., and KISH, P. E. (1981). The growth and organisation of the optic nerve and tract in juvenile and adult goldfish. J. Neurosci. 1:793-811.

EAster, S. S. JR. and Stuermer, C. A. O. (1984). An evaluation of the hypothesis of shifting terminals in goldfish optic tectum. J. Neurosci. 4:1052-1063.

GIERER, A. (1987). Directional cues for growing axons forming the retinotectal projection. Development 101:479-489.

Godement, P. and Bonhoefrer, F. ( 1989). Cross-species recognition of tectal cues by retinal fibers in vitro. Development 106:313-320.

Goodman, C. S. and Shatz, C. J. (1993). Developmental mechanisms that generate precise patterns of neuronal connectivity. Cell 72(Suppl.):77-98.

HAirston, N. G., JR., LI, K. T., and EASTER, S. S., JR. (1982). Fish vision and the detection of planktonic prey. Science 218:1240-1242.

HARRIS, W. A. (1984). Axonal pathfinding in the absence of normal pathways and impulse activity. $J$. Neurosci. 4:1153-1162.

Harris, W. A., HOlt, C. E., and BonhoefFer, F. (1987). Retinal axons with and without their somata, growing to and arborizing in the tectum of Xenopus embryos: a time lapse video study of single fibers in vivo. Development 101:123-133.

Hartlieb, E. and Stuermer, C. A. O. (1987). Pathfinding and target selection of goldfish retinal axons regenerating under TTX-induced impulse blockade. J. Comp. Neurol. 284:148-168.

Holt, C. E. and HARRIS, W. A. (1993). Position, guidance, and mapping in the developing visual system. $J$. Neurobiol. 24:1400-1422.

JaCk, J., GoOday, D., Wilson, M., and Gaze, M. (1991). Retinal axons in Xenopus show different behaviour patterns on various glial substrates in vitro. Anat. Embryol. 183:193-203.

KaEthner, R. J. and Stuermer, C. A. O. (1992). Dynamics of terminal arbor formation and target approach of retinotectal axons in living zebrafish embryos: a time lapse study of single axons. $J$. Neurosci. 12:3257-3271.

Kobayashi, T., NAKamuRA, H., and YaSUDA, $M$. (1990). Disturbance of refinement of retinotectal projection in chick embryos by tetrodotoxin and grayanotoxin. Development 57:29-35.

LaEssing, U., Giordano, S., LotTSPeich, F., and STUERMER, C. A. O. ( 19XX). Molecular characterization of fish Neurolin: a growth associated cell surface protein and member of the Ig-superfamily with similarities to chick DM-Grasp/SC-1/BEN. Differentiation (in press).
MEISTER, M., WONG, R. O. L., BAYLOR, D. A., and SHATZ, C. J. (1991). Synchronous bursts of action potentials in ganglion cells of the developing mammalian retina. Science 252:939-943.

NAKAMURA, H. and O'LeARY, D. D. M. (1989). Inaccuracies in initial growth and arborization of chick retinotectal axons followed by course corrections and axon remodeling to develop topographic order. $J$. Neurosci. 9:3776-3795.

ReH, T. A. and CONSTANTINE-PATON, M. (1984). Retinal ganglion cell terminals change their projection sites during larval development of Rana pipiens. $J$. Neurosci. 4:442-457.

Reh, T. A. and Constantine-Paton, M. (1985). Growth cone target interactions in the frog retinotectal pathway. J. Neurosci. Res. 13:89-100.

O'Rourke, N. A. and Fraser, S. E. (1990). Dyhamic changes in optic fiber terminal arbors lead to retinotopic map formation: an in vivo confocal microscopic study. Neuron 5:159-171.

RAYMOND, P. A. ( 1986). Movement of retinal terminals in goldfish optic tectum predicted by analysis of neuronal proliferation. J. Neurosci. 6:2479-2488.

Sakaguchi, D. S. and MurPhey, R. K. (1985). Map formation in the developing Xenopus retinotectal system: an examination of ganglion cell terminal arborizations. J. Neurosci. 5:3228-3245.

SCAlia, F. and Matsumoto, D. E. (1985). The morphology of growth cones of regenerating optic nerve axons. J. Comp. Neurol. 231:323-338.

SCHMidT, J. T. and Buzzard, M. (1993). Activity-driven sharpening of the retinotectal projection in goldfish: development under stroboscopic illumination prevents sharpening. J. Neurobiol. 24:384-399.

SChmidt, J. T., Turcotte, J. C., Buzzard, M., and TIEMAN, D. G. (1988). Staining of regenerated optic arbors in goldfish tectum: progressive changes in immature arbors and a comparison of mature regenerated arbors with normal arbors. J. Comp. Neurol. 269:565-591.

Shatz, C. J. and STR YKer, M. P. (1988). Prenatal tetrodotoxin infusion blocks segregation of retinogeniculate afferents. Science 242:87-89. ..

Simon, D. K. and O'Leary, D. D. M. (1990). Limited topographic specificity in the targeting and branching of mammalian retinal axons. Dev. Biol. 137:125-134.

Simon, D. K. and O'LEARY, D. D. M. (1992). Development of topographic order in the mammalian retinocollicular projection. J. Neurosci. 12:1212-1232.

Sretavan, D. W., Shatz, C. J., and Stryker, M. P. (1988). Modification of retinal ganglion cell axon morphology by prenatal infusion of tetrodotoxin. $\mathrm{Na}$ ture 336:468-471.

Strittmatter, S. M. and Fishman, M. C. (1991). The neuronal growth cone as a specialized transduction system. Bioessays 13:127-134.

StUermer, C. A. O. and EASter, S. S. JR. (1984). A comparison of the normal and regenerated retinotectal pathways of goldfish. J. Comp. Neurol. 223:57-76. 
STUERMER, C. A. O. ( 1984). Rules for retinotectal terminal arborizations in the goldfish optic tectum: a wholemount study. J. Comp. Neurol. 229:214-232.

STUERMER, C. A. O. (1988). Retinotopic organization of the developing retinotectal projection in the zebrafish embryo. $J$. Neurosci. 8:45 I 3-4530.

STUERMER, C. A. O. and RAYMOND, P. A. (1989). Developing retinotectal projection in larval goldfish. $J$. Comp. Neurol. 281:630-640.

Stuermer, C. A. O., Rohrer, B., and Münz, H. (1990). Development of the retinotectal projection in zebrafish embryos under TTX-induced neural-impulse blockade. J. Neurosci. 10:3615-3626.

STUERMER, C. A. O. (1993). Die Navigation des Wachstumskegels und die Verschaltung des Nervennetzes. In: Verhandlungen der Gesellschaft Deutscher Naturforscher und Ärzte, Aachen. Aachen. Wiss. Verlags GmbH, Stuttgart, pp. 275-297.
THOMPSON, I. and HoLr, C. (1989). Effects of intraocular tetrodotoxin on the development of the retinocollicular pathway in the Syrian hamster. J. Comp. Neurol. 282:371-388

TOSNEY, K. and LANDMESSER, L. T. (1985). Growth cone morphology and trajectory in the lumbosacral region of the chick embryo. J. Neurosci. 5:2345-2358.

VIELMETTER, J. and STUERMER, C. A. O. (1989). Goldfish retinal axons respond to position-specific properties of tectal cell membranes in vitro. Neuron 2:13311339.

WAlter, J., Kern-Veits, B., Huf, J., Stolze, B., and BONHOEFFER, F. ( 1987). Recognition of position-specific properties of tectal cell membranes by retinal axons in vitro. Development 101:685-696.

YounG, S. H. and Poo, M.-M. (1983). Spontaneous release of transmitter from growth cones of embryonic neurons. Nature 305:634-637. 